\title{
Rapid Photocatalytic Degradation of Methylene Blue under High Photon Flux UV Irradiation: Characteristics and Comparison with Routine Low Photon Flux
}

\author{
Qian Zhang, Chaolin Li, and Ting Li \\ Environmental Science \& Engineering Research Center, Shenzhen Graduate School, Harbin Institute of Technology, \\ Shenzhen 518055, China \\ Correspondence should be addressed to Chaolin Li, lichaolinhit@gmail.com
}

Received 9 January 2012; Accepted 29 February 2012

Academic Editor: Manickavachagam Muruganandham

Copyright ( 2012 Qian Zhang et al. This is an open access article distributed under the Creative Commons Attribution License, which permits unrestricted use, distribution, and reproduction in any medium, provided the original work is properly cited.

This study examined the photocatalytic degradation efficiency under high UV photon flux (intensity normalized by photon energy) irradiation; the incident UV photon flux was $1.71 \times 10^{-6}-3.13 \times 10^{-6}$ einstein $\mathrm{cm}^{-2} \mathrm{~s}^{-1}$ made by a super high-intensity UV apparatus. A comparative study between high photon flux photocatalytic process and routine low photon flux photocatalytic process for methylene blue degradation has been made in aqueous solution. The experimental results showed that under the best conditions of high UV photocatalytic reaction 99\% decolorization and 95\% TOC removal of $20 \mathrm{mg} \mathrm{L}^{-1}$ methylene blue could be achieved in $30 \mathrm{~s}$ and $120 \mathrm{~s}$ of UV irradiation time, respectively. To the best of our knowledge, photocatalytic decolorization and photocatalytic degradation of dyes in such a short time has not been reported. Aiming at the low photonic efficiency in high photon flux photocatalytic process, we found that reducing the density of excited electron-hole appropriately could improve initial apparent photonic efficiency effectively. The TOC experiments under high UV photon flux showed a faster mineralization rate and a different mineralization process compared to that under low UV photon flux.

\section{Introduction}

Heterogeneous photocatalytic oxidation has potential applications for the treatment of waste water with dilute concentration of organic compounds because it effectively oxidizes a large number of chemical pollutants [1]. Among the most popular semiconductors studied, $\mathrm{TiO}_{2}$ is one of the best candidates [2]. However, the commercial application of this method for the treatment of aqueous solutions is limited by both the long time of the process and the low efficiency in the use of the radiation [3]. If $\mathrm{TiO}_{2}$ photocatalysis is to have a commercial future as a method for water purification, reaction time must compare favorably with those of its competitors ( $\mathrm{UV} / \mathrm{H}_{2} \mathrm{O}_{2}, \mathrm{UV} / \mathrm{O}_{3}$, photo Fenton, etc.). On this basis, many studies have been conducted to improve the photocatalytic reaction rate such as the doping of some elements or compounds into $\mathrm{TiO}_{2}[4]$, increasing the external surface area [5], improving photocatalytic reactor design [6], and so forth. Light photon flux (intensity normalized by photon energy) is one of the most parameters in photocatalytic reaction, and high UV intensity could compensate for the low photocatalytic efficiency of $\mathrm{TiO}_{2}$ itself [7]. Ollis et al. [8] observed that the relationship between UV intensity and degradation rate changed from first order $(K \propto I)$ to half order $\left(K \propto I^{0.5}\right)$ when the UV intensity increased beyond a certain value (approximately $25 \mathrm{~mW} \mathrm{~cm}^{-2}$ ), and then changed from half order $\left(K \propto I^{0.5}\right)$ to zero order $\left(K \propto I^{0}\right)$ when the UV intensity reached a high level. Many similar studies have confirmed this finding [9-11]. Because the efficiency of photocatalytic reaction declines under extremely high UV intensity, the application of improving photocatalytic reaction rate by increasing UV intensity is not fully developed. However, the high photon flux UV irradiation can effectively lessen the photocatalytic reaction time [12]; therefore, it is important to improve the understanding of the high UV intensity photocatalytic reaction and to increase UV light efficiency of the reaction. 
The aim of this paper was to determine the effectiveness of photocatalytic processes based on high photon flux irradiation ranging from $1.71 \times 10^{-6}$ to $3.13 \times 10^{-6}$ einstein $\mathrm{cm}^{-2} \mathrm{~s}^{-1}$ (approximately UV intensity from 550 to 1000 $\mathrm{mW} \mathrm{cm}{ }^{-2}$ ) in the photocatalytic degradation of a typical basic dye, methylene blue (MB), from aqueous solution. The operating conditions were adjusted to permit a comparison between high UV photon flux photocatalytic process (HUP) and routine low UV photon flux photocatalytic process (LUP) (photon flux ranging $0.667 \times 10^{-9}$ to $3.07 \times 10^{-9}$ einstein $\mathrm{cm}^{-2} \mathrm{~s}^{-1}$ approximately equal to UV intensity from 0.4 to $2 \mathrm{~mW} \mathrm{~cm}^{-2}$ ). Three different criteria were used to contrast both processes: (i) reaction rate and reaction time, (ii) the initial apparent photonic efficiency, and (iii) mineralization rate and mineralization degree.

\section{Material and Methods}

2.1. Materials and Reagents. The photocatalyst was titania Degussa P-25 (anatase/rutile $=7 / 3$, surface area $=50 \mathrm{~m}^{2} \mathrm{~g}^{-1}$, nonporous particles, mean size $=30 \mathrm{~nm}$ ). MB was obtained from Hongyan chemical Co., Ltd., $(\geq 99 \%)$. Potassium ferrioxalate was obtained from Hefei Asialon chemical Co., Ltd., $(\geq 99 \%)$. Solutions were prepared using water from a Millipore Waters Milli-Q purification unit.

2.2. Light Source and Photoreactor. Two kinds of UV lamp were used: (a) a $250 \mathrm{~W}$ UV high pressure mercury lamp (Ushio Inc, Japan) with a quartz reflector were used as a high photon flux light source. The incident photon flux entering the photoreactor was varied from $1.71 \times 10^{-6}$ to $3.13 \times$ $10^{-6}$ einstein $\mathrm{cm}^{-2} \mathrm{~s}^{-1}$. (b) An $8 \mathrm{~W}$ black light lamp (Philips TL 6W/08) was used as a low photon flux light source. The incident photon flux entering the photoreactor was varying from $0.667 \times 10^{-9}$ to $3.07 \times 10^{-9}$ einstein $\mathrm{cm}^{-2} \mathrm{~s}^{-1}$. The spectral distributions of both lamps are shown in Figure 1.

The schematic diagram of the photoreactor apparatus is shown in Figure 2. All the irradiation experiments were conducted in a glass cylinder of $35.6 \mathrm{~mm}$ diameter and $45 \mathrm{~mm}$ height. The top of the glass cylinder was open to the atmosphere. The lamp was placed at the focal axis of the quartz reflector and an optical filter was inserted to cut off the long wavelength components $(\lambda>425 \mathrm{~nm})$ for avoiding heating the aqueous solution (no quartz reflector and optical filter for the black light lamp). A sliding shutter with electronic time switch was used to determine exactly the moment at which the photocatalytic reaction started or ended. Between the lamp and the reactor, there are neutral density filters of different transmissions to change the photon flux of the incident irradiation on the reactor. Different photon fluxes were measured inside the reactor cylinder using potassium ferrioxalate method [13]. A magnetic stirrer located at the bottom of the glass cylinder kept the $\mathrm{TiO}_{2}$ particles suspended during the irradiation. The photoreactor, the reflector, and the lamp were enclosed in a box to ensure safe operation and to prevent the entrance of extraneous light.

2.3. Experiments Procedure. All experiments were in the following range of the experimental variables: the incident photon flux of the high photon flux light source was between $1.71 \times 10^{-6}$ and $3.13 \times 10^{-6}$ einstein $\mathrm{cm}^{-2} \mathrm{~s}^{-1}$; the incident photon flux of the low photon flux light source was between $0.667 \times 10^{-9}$ and $3.07 \times 10^{-9}$ einstein $\mathrm{cm}^{-2} \mathrm{~s}^{-1}$; temperature $25^{\circ} \mathrm{C}$ (room temperature); $\mathrm{MB}$ initial concentration $20 \mathrm{mg} \mathrm{L}^{-1}$; $\mathrm{TiO}_{2}$ concentration between $0.25 \mathrm{~g} \mathrm{~L}^{-1}$ and $1.5 \mathrm{~g} \mathrm{~L}^{-1}$.

Each run adhered to the following protocol: (i) the lamp was turned on, allowing for $40 \mathrm{~min}$ to stabilizing their operation, and a suspension of $\mathrm{TiO}_{2}$ and $\mathrm{MB}$ was mixed well in the dark at least $60 \mathrm{~min}$ for reaching an equilibrated adsorption as steady-state concentrations. (ii) $10 \mathrm{~mL}$ of $\mathrm{MB}$ solution was injected in the photoreactor. (iii) The solution was then irradiated by UV light and sample was collected at specific time to measure the MB concentration. (iv) Simple suspensions were filtered by a $0.45 \mu \mathrm{m}$ membrane filter to remove the $\mathrm{TiO}_{2}$ powder. Samples at different reaction time were obtained by repeating steps (ii), (iii), and (iv). The decolorization efficiency was tested in terms of the changes of the UV-vis absorbance of MB. The absorbance intensity of MB was determined by an UV-vis spectrophotometer (UV-2450 SHIMADZU) with a $1 \mathrm{~cm}$ path length spectrometric quartz cell. Total organic carbon (TOC) was analyzed with a total organic carbon analyzer (Analytik Jena multi-N/C 3100).

\section{Results and Discussion}

3.1. Preliminary Tests. Preliminary tests using different experimental conditions were carried out to make sure that the dye degradation was mainly due to the photocatalytic reaction. The results are as follows. The MB concentration decreased about $4 \%$ in the darkness in the presence of $\mathrm{TiO}_{2}$. This suggests a weak adsorption of the dye molecules on $\mathrm{TiO}_{2}$. In the absence of $\mathrm{TiO}_{2}$, the $\mathrm{MB}$ concentration decreased about $1 \%$ under low photon flux irradiation (3.07 $\times 10^{-9}$ einstein $\mathrm{cm}^{-2} \mathrm{~s}^{-1}$ ) after $1 \mathrm{~h}$ and the $\mathrm{MB}$ concentration almost remained unchanged at high photon flux irradiation $\left(3.13 \times 10^{-6}\right.$ einstein $\left.\mathrm{cm}^{-2} \mathrm{~s}^{-1}\right)$ after $60 \mathrm{~s}$. This indicates that the dye degradation by the direct photolysis only is unimportant. Therefore, the reduction of dye concentration is primarily caused by the photocatalytic reaction.

3.2. UV Irradiation Intensity and Irradiation Time. In order to compare different UV irradiation intensities and irradiation times on the rate of photocatalytic decolourization, a set of tests was carried out in both HUP and LUP, and the results are shown in Figures 3(a) and 3(b). In all cases, MB was removed rapidly from the beginning and as time elapsed the decolorization rate decreased. The decolorization percentage of $\mathrm{MB}$ was $>90 \%$ in reaction time $15 \mathrm{~s}$ and $>99 \%$ in $30 \mathrm{~s}$ in HUP with a UV photon flux $3.13 \times 10^{-6}$ einstein $\mathrm{cm}^{-2} \mathrm{~s}^{-1}$ (Figure 3(a)), whereas the decolorization percentage of $\mathrm{MB}$ was $>90 \%$ in $40 \mathrm{~min}$ and $>96 \%$ in $60 \mathrm{~min}$ in LUP with a UV photon flux $3.07 \times 10^{-9}$ einstein $\mathrm{cm}^{-2} \mathrm{~s}^{-1}$ (Figure 3(b)). It is clear that increasing the UV photon flux enhances the rate of decolorization remarkably.

Figures $3(\mathrm{a})$ and $3(\mathrm{~b})$ also show that the plots of $\ln \left(\mathrm{C} / \mathrm{C}_{0}\right)$ versus irradiation time for HUP and LUP were linear, which suggest that both the photocatalytic processes approximately 


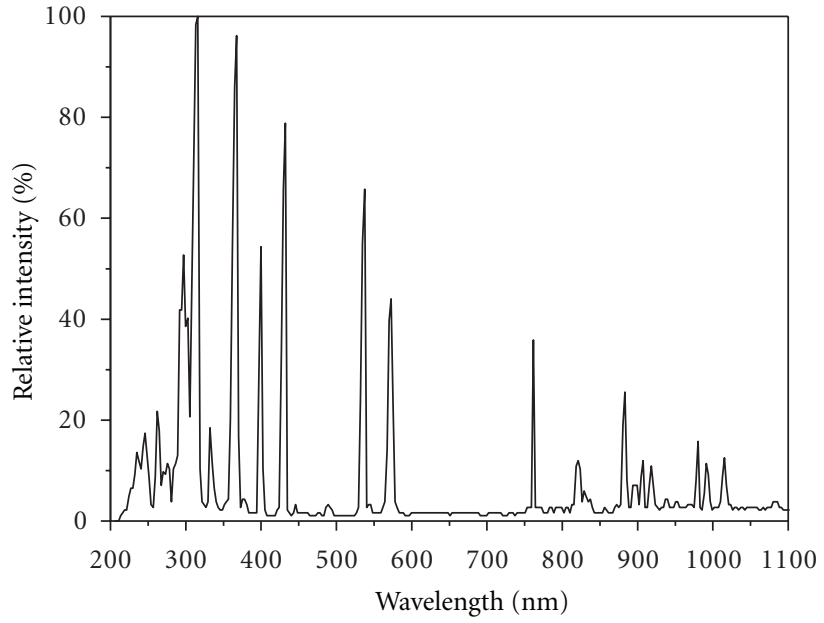

(a)

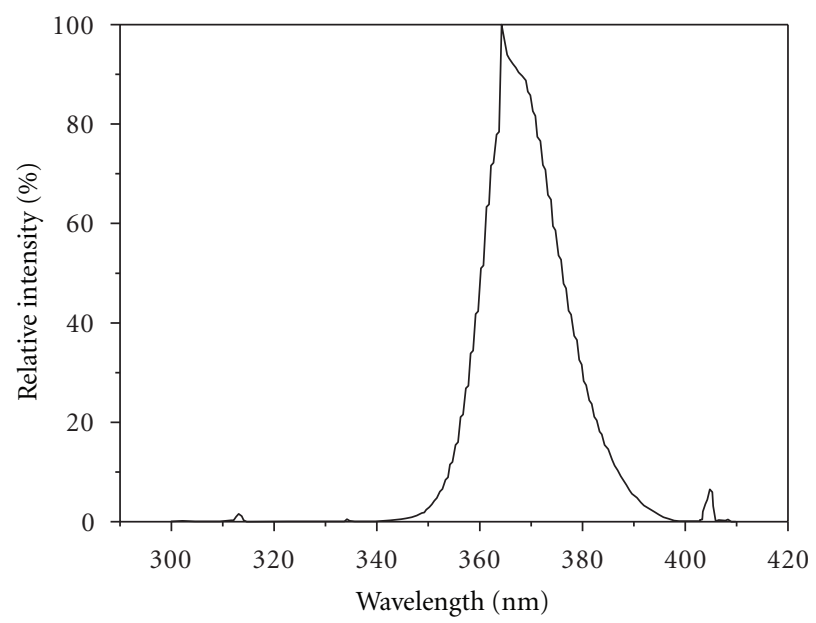

(b)

FIGURE 1: UV spectra of $250 \mathrm{~W}$ UV high pressure mercury lamp (a) and $8 \mathrm{~W}$ black light lamp (b).

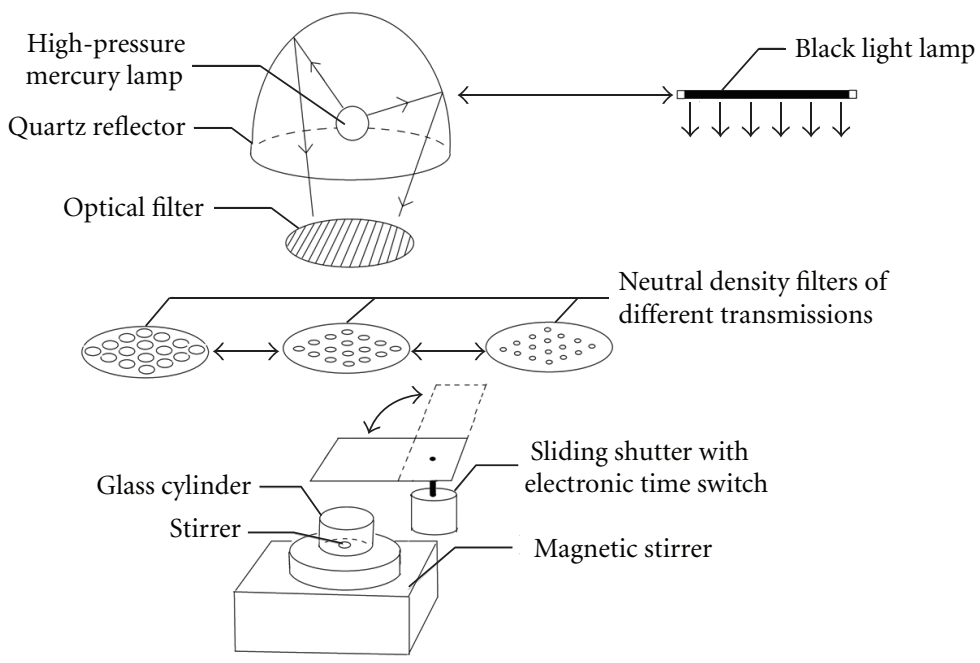

FIGURE 2: Schematic diagram of the photoreactor apparatus.

follow pseudo-first-order kinetics. Rate constants were estimated from the slopes of $\ln \left(\mathrm{C} / \mathrm{C}_{0}\right)$ versus time. The pseudofirst-order constants for HUP with photon fluxes $1.71 \times$ $10^{-6}, 1.99 \times 10^{-6}, 2.28 \times 10^{-6}, 2.56 \times 10^{-6}, 2.85 \times 10^{-6}$, and $3.13 \times 10^{-6}$ einstein $\mathrm{cm}^{-2} \mathrm{~s}^{-1}$ were $0.1103,0.1182,0.1245$, $0.1334,0.1421$, and $0.1513 \mathrm{~s}^{-1}$, and for LUP with photon fluxes $0.667 \times 10^{-9}, 1.03 \times 10^{-9}, 1.33 \times 10^{-9}, 1.71 \times 10^{-9}$, $2.28 \times 10^{-9}, 3.07 \times 10^{-9}$ einstein $\mathrm{cm}^{-2} \mathrm{~s}^{-1}$ were $2.5 \times 10^{-4}$, $3.8 \times 10^{-4}, 5.1 \times 10^{-4}, 6.6 \times 10^{-4}, 8.5 \times 10^{-4}, 1.1 \times 10^{-3} \mathrm{~s}^{-1}$, respectively. We suggest that the significant improvement in $\mathrm{MB}$ decolorization is mainly due to the more hydroxyl radicals that are produced by more radiations falling on the catalyst surface [14].

There were two different reaction rate regimes as a function of UV photon flux by different UV lamps. It is found that the reaction rate depends on photon flux of UV light $I$ in a power law [8] such as

$$
r=r^{\prime \prime} I^{\alpha},
$$

where $r^{\prime}$ is the reaction constant independent of photon flux. The exponent value $(\alpha)$ could be estimated from the reaction rates and photon fluxes. The value $(\alpha)$ is 0.512 for HUP and 0.9813 for LUP. Both of the values $(\alpha)$ show good fits with the data and the correlation coefficients are $R^{2}=0.9906 R^{2}=0.9977$, respectively. These results indicate that in our experiment the photocatalytic decolorization rate increases with the square root of photon flux under high photon flux in the range from $1.71 \times 10^{-6}$ to 3.13 $\times 10^{-6}$ einstein $\mathrm{cm}^{-2} \mathrm{~s}^{-1}$ and the photocatalytic degradation rate increase linearly with photon flux under low photon 


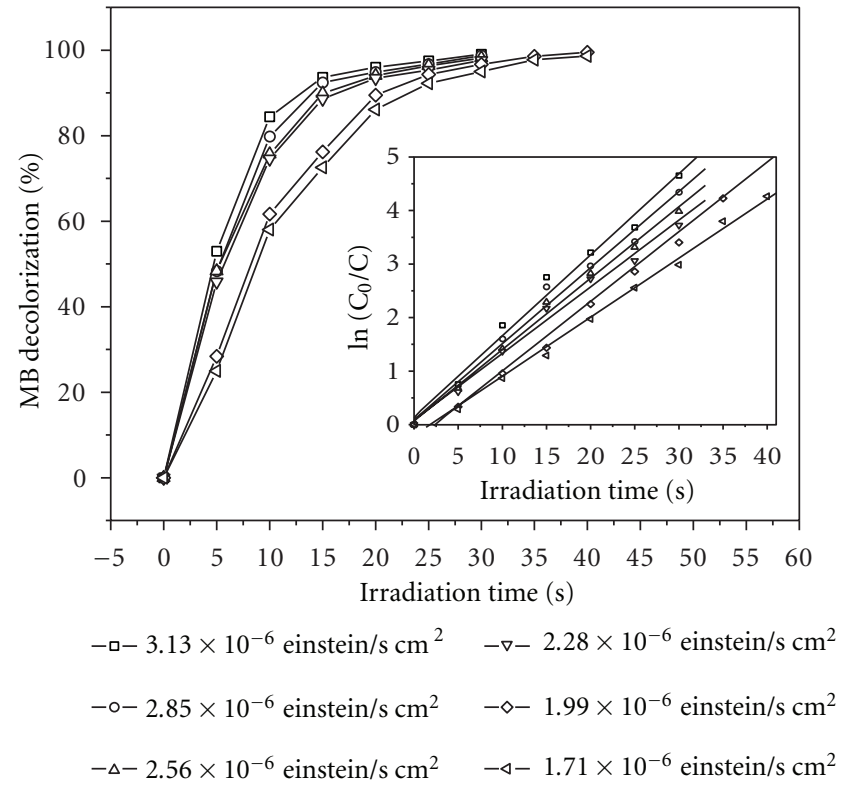

(a)

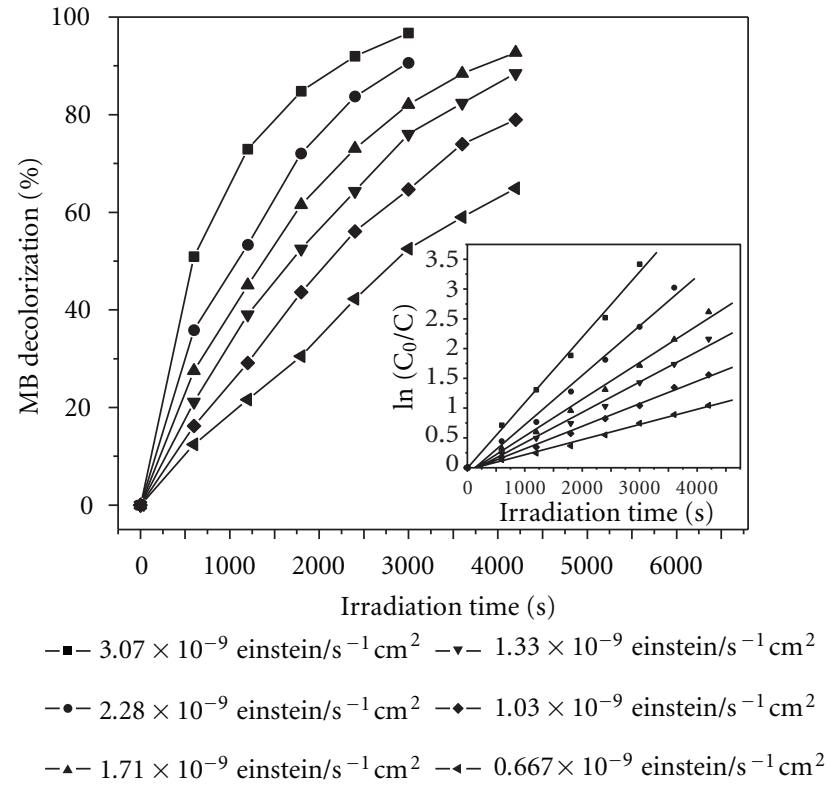

(b)

Figure 3: Photocatalytic decolorization of MB versus irradiation time by (a) $\mathrm{HUP}_{\text {and }}$ (b) LUP. (Experimental conditions: $\mathrm{TiO}_{2}, 1 \mathrm{gL}^{-1}$; $\mathrm{MB}$ initial concentration $20 \mathrm{mg} \mathrm{L}^{-1}$ ).

flux in the range from $0.667 \times 10^{-9}$ to $3.07 \times 10^{-9}$ einstein $\mathrm{cm}^{-2} \mathrm{~s}^{-1}$. The tendency of the effect by photon flux is in agreement with some studies, and in these reports the authors attributed this to electron-hole recombination [911]. The rate of electron-hole formation exceeds the rate photocatalytic oxidation under high photon flux, resulting in electron-hole recombination $[9-11,14]$.

3.3. Initial Apparent Photonic Efficiency. The photonic efficiency $(\xi)$ describing the effectiveness of light conversion to product in heterogeneous, light scattering systems, is directly proportional to the quantum yield and may be considered to be the lower limit of this more commonly used measure of light [15].

In our case, the initial apparent photonic efficiency was calculated from the ratio of the initial reaction rate of photooxidation $\left(\mathrm{mol} \mathrm{L}^{-1} \mathrm{~s}^{-1}\right)$ to the rate of incident photons reaching the reactor as obtained by chemical actinometry (einstein $\mathrm{L}^{-1} \mathrm{~s}^{-1}$ ) [16].

Table 1 summarizes initial apparent photonic efficiencies of photocatalytic decolorization of MB for HUP and LUP. The initial apparent photonic efficiencies at high photon fluxes were lower than the case of low photon fluxes, which illustrated that high photon fluxes photocatalytic processes had lower light energy utilization efficiency. This result satisfies the law that the initial apparent photonic efficiency decreases as the light intensity increases, and this is in agreement with other authors $[17,18]$.

The explanation of the lower initial apparent photonic efficiencies is that high photon flux causes lower effect on reaction rate (from first order $(r \propto I)$ to half order $\left(r \propto I^{0.5}\right)$ in Section 3.2), and therefore decreases the initial apparent
TABLE 1: Relative photonic efficiencies of photocatalytic degradation of $\mathrm{MB}$ under different photon fluxes.

\begin{tabular}{|c|c|c|c|}
\hline \multicolumn{2}{|c|}{$\begin{array}{l}\text { High photon flux } \\
\text { photocatalytic process }\end{array}$} & \multicolumn{2}{|c|}{$\begin{array}{l}\text { Low photon flux photocatalytic } \\
\text { process }\end{array}$} \\
\hline $\begin{array}{l}\text { Photon flux } \\
\left(10^{-6} \text { einstein }\right. \\
\left.\mathrm{cm}^{-2} \mathrm{~s}^{-1}\right)\end{array}$ & $\begin{array}{l}\text { Relative photonic } \\
\text { efficiencies }(\%)\end{array}$ & $\begin{array}{l}\text { Photon flux } \\
\left(10^{-9} \text { einstein }\right. \\
\left.\mathrm{cm}^{-2} \mathrm{~s}^{-1}\right)\end{array}$ & $\begin{array}{c}\text { Relative } \\
\text { photonic } \\
\text { efficiencies }(\%) \\
\end{array}$ \\
\hline 3.13 & 0.302 & 3.07 & 2.23 \\
\hline 2.85 & 0.311 & 2.28 & 2.33 \\
\hline 2.56 & 0.325 & 1.71 & 2.41 \\
\hline 2.28 & 0.341 & 1.33 & 2.40 \\
\hline 1.99 & 0.371 & 1.03 & 2.37 \\
\hline 1.71 & 0.403 & 0.667 & 2.43 \\
\hline
\end{tabular}

photonic efficiency. At low light intensity reactions involving electron-hole separation were predominant and electronhole recombination was negligible, whereas at increased light intensity electron-hole pair separation competed with recombination, thereby causing lower influence on initial apparent photonic efficiency [9-11, 14]. Based on this theory, we infer that the decreasing of the $\mathrm{TiO}_{2}$ concentration properly may decrease the density of excited electronhole pairs, and thereby ease the electron-hole recombination in high photon flux photocatalytic reaction. As a test of the hypothesis, we examined the relationship between the $\mathrm{TiO}_{2}$ concentration and the initial apparent photonic efficiency under both low and high photon flux. And we kept constant the product of $\mathrm{TiO}_{2}$ concentration and the optical path length in different volume sample in order to modify 
the $\mathrm{TiO}_{2}$ concentration without changing the total amount of $\mathrm{TiO}_{2}$.

Series of experiments were designed as follows: (i) sample optical path length $0.67 \mathrm{~cm}$, sample volume $6.7 \mathrm{~mL}, \mathrm{TiO}_{2}$ concentration $1.5 \mathrm{~g} \mathrm{~L}^{-1}, \mathrm{MB}$ concentration $20 \mathrm{mg} \mathrm{L}^{-1}$; (ii) sample optical path length $1 \mathrm{~cm}$, sample volume $10 \mathrm{~mL}, \mathrm{TiO}_{2}$ concentration $1 \mathrm{gL}^{-1}, \mathrm{MB}$ concentration $20 \mathrm{mg} \mathrm{L}^{-1}$; (iii) sample optical path length $2 \mathrm{~cm}$, sample volume $20 \mathrm{~mL}$, $\mathrm{TiO}_{2}$ concentration $0.5 \mathrm{~g} \mathrm{~L}^{-1}, \mathrm{MB}$ concentration $20 \mathrm{mg} \mathrm{L}^{-1}$; (iv) sample optical path length $3 \mathrm{~cm}$, sample volume $30 \mathrm{~mL}$, $\mathrm{TiO}_{2}$ concentration $0.33 \mathrm{~g} \mathrm{~L}^{-1}, \mathrm{MB}$ concentration $20 \mathrm{mg} \mathrm{L}^{-1}$; (v) sample optical path length $4 \mathrm{~cm}$, sample volume $40 \mathrm{~mL}$, $\mathrm{TiO}_{2}$ concentration $0.25 \mathrm{~g} \mathrm{~L}^{-1}, \mathrm{MB}$ concentration $20 \mathrm{mg} \mathrm{L}^{-1}$; (vi) sample optical path length $5 \mathrm{~cm}$, sample volume $50 \mathrm{~mL}, \mathrm{TiO}_{2}$ concentration $0.20 \mathrm{~g} \mathrm{~L}^{-1}, \mathrm{MB}$ concentration $20 \mathrm{mg} \mathrm{L}^{-1}$; (vii) sample optical path length $6 \mathrm{~cm}$, sample volume $60 \mathrm{~mL}, \mathrm{TiO}_{2}$ concentration $0.17 \mathrm{~g} \mathrm{~L}^{-1}, \mathrm{MB}$ concentration $20 \mathrm{mg} \mathrm{L}^{-1}$; (viii) sample optical path length $7 \mathrm{~cm}$, sample volume $70 \mathrm{~mL}, \mathrm{TiO}_{2}$ concentration $0.14 \mathrm{~g} \mathrm{~L}^{-1}, \mathrm{MB}$ concentration $20 \mathrm{mg} \mathrm{L}^{-1}$. As optical path length changed, adjusted the height of photoreactor to keep a constant distance between light source and the solution surface, which maintained a constant photon flux in each experiment. Experiments were carried out under both high and low photon flux. The initial apparent photonic efficiencies under these conditions are summarized in Table 2. It could be clearly observed that under low photon flux the initial apparent photonic efficiency steadily decreased with optical path length. On the contrary, under high photon flux, initial apparent photonic efficiency firstly increased with the increase of optical path length from 0.67 to $3 \mathrm{~cm}$. When the optical path length increased further than $3 \mathrm{~cm}$, the initial apparent photonic efficiency decreased. The results in low photon flux experiments are mainly due to the fact that long path lengths will promote absorbance of light by $\mathrm{MB}$ and other solution chemicals, as the Lambert-Beer law states. And this is in agreement with other reports [19]. In high photon flux experiments, as the optical path length increased from 0.67 to $3 \mathrm{~cm}$, the absorption of UV by MB and other solution chemicals also increased with the optical length path. However, instead of decreasing, the initial apparent photonic efficiency increased. We deduce that the increase of initial apparent photonic efficiency is probably due to the decrease of electron-hole recombination. It means that under high photon flux decreasing $\mathrm{TiO}_{2}$ concentration could decrease the density of excited electron-hole pairs and reduce the electron-hole recombination. As optical path length above $3 \mathrm{~cm}$, the decline in initial apparent photonic efficiency was due to the increased incident photons beings absorbed by a longer path length of the suspension in excess of the decrease of electron-hole recombination. The results in this study clearly prove our hypothesis and indicate that the reduction in the density of excited electron-hole could actually improve the photonic efficiency in high photon flux photocatalytic reaction.

3.4. Mineralization. It is well known that complete decolorization of $\mathrm{MB}$ does not mean that the dye is completely mineralized into $\mathrm{CO}_{2}$ and $\mathrm{H}_{2} \mathrm{O}$. Hence, it is necessary to simultaneously investigate the mineralized process. TOC
TABLE 2: Relative photonic efficiencies of photocatalytic degradation of MB with different optical path length and $\mathrm{TiO}_{2}$ concentration.

\begin{tabular}{lcc}
\hline $\begin{array}{l}\text { Optical path length } \\
\text { (cm) }\end{array}$ & $\begin{array}{c}\text { Initial apparent photonic efficiency (\%) } \\
\text { Photon flux } \\
\text { Photon flux } \\
\times 10^{-6} \text { einstein } \\
\mathrm{cm}^{-2} \mathrm{~s}^{-1}\end{array}$ & $\begin{array}{c}3.07 \times 10^{-9} \\
\text { einstein } \mathrm{cm}^{-2} \mathrm{~s}^{-1}\end{array}$ \\
\hline (i) 0.67 & 0.235 & 2.25 \\
(ii) 1 & 0.302 & 2.23 \\
(iii) 2 & 0.329 & 2.01 \\
(iv) 3 & 0.335 & 1.82 \\
(v) 4 & 0.319 & 1.52 \\
(vi) 5 & 0.298 & 1.36 \\
(vii) 6 & 0.264 & 1.18 \\
(viii) 7 & 0.242 & 1.09 \\
\hline
\end{tabular}

values have been related to the total concentration of organic in the solution and the decrease of TOC reflects the degree of mineralization at the end of the photocatalytic process. Mineralization of MB was studied by monitoring TOC loss in the dye solution.

The TOC removal and decolorization efficiencies with irradiation time are shown in Figure 5 the TOC removal and decolorization efficiencies with irradiation time in LUP. At the beginning of the reaction, an initial period of constant or slowly decreasing TOC values occurred. The inflect point corresponded to a reaction time of $60 \mathrm{~min}$, which was equal to the decolorization time of MB. After the complete decolorization of the solution, the TOC values decreased, and then reached a plateau at the reaction time of $300 \mathrm{~min}$. The results demonstrate that in LUP mineralization step starts only when decolorization is almost complete. The initial period of constant or slowly decreasing TOC values could correspond to the fact that $\mathrm{MB}$ molecules are decomposed to lower-molecular-weight compounds and the intermediates still contribute to the TOC of solution. The emergence of mineralization plateau indicates that the total oxidation is nearing completion, corresponding to the oxidation of most stable products. The tendency of the mineralization process is similar to the previous results [20].

However, the photocatalytic mineralization of MB solution in HUP had a different mineralization procedure than the LUP. As shown in Figure 4(a), the TOC values decreased approximately exponentially with reaction time from the beginning of the reaction. The continuous decay of TOC value confirmed the progressive mineralization of $\mathrm{MB}$ under high photon flux. This pattern meant that during the decolorization step (irradiation time $0-30 \mathrm{~s}$ ) there was obvious decrease of the TOC value, which was due to the fact that MB molecules were decomposed to intermediate product and further oxidized to the intermediate product simultaneously.

UV photon flux determines the amount of photons injected into the solution. Under high photon flux irradiation, the photocatalyst could absorb more photons, leading to more electron-hole pairs on the photocatalyst surface. We 


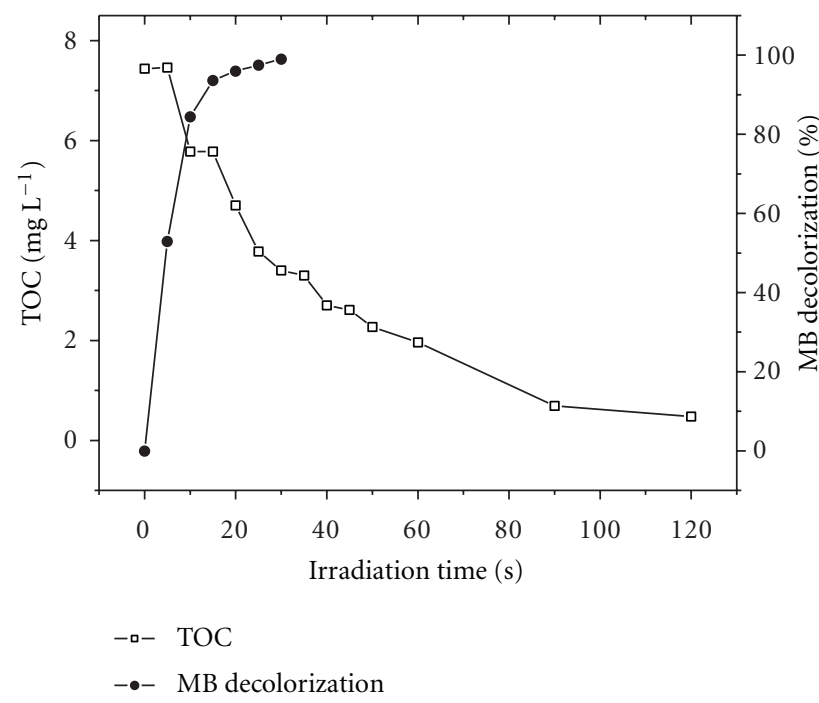

(a)

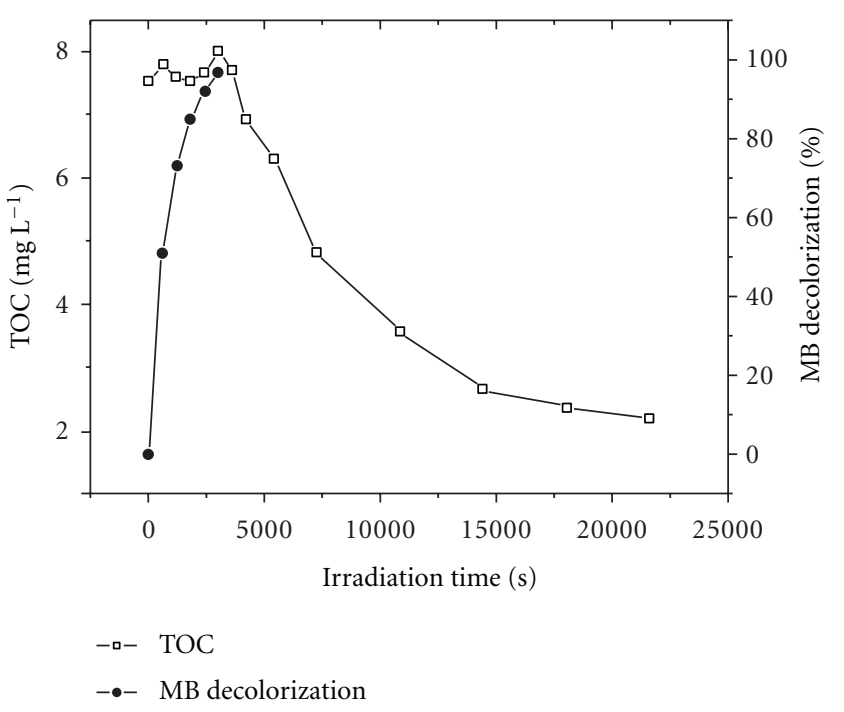

(b)

FIGURE 4: The TOC removal and decolorization efficiencies versus irradiation time by (a) HUP and (b) LUP. (Experimental conditions:

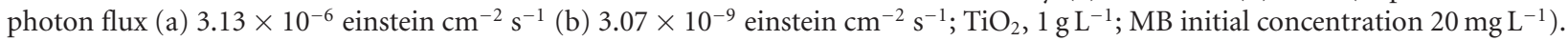

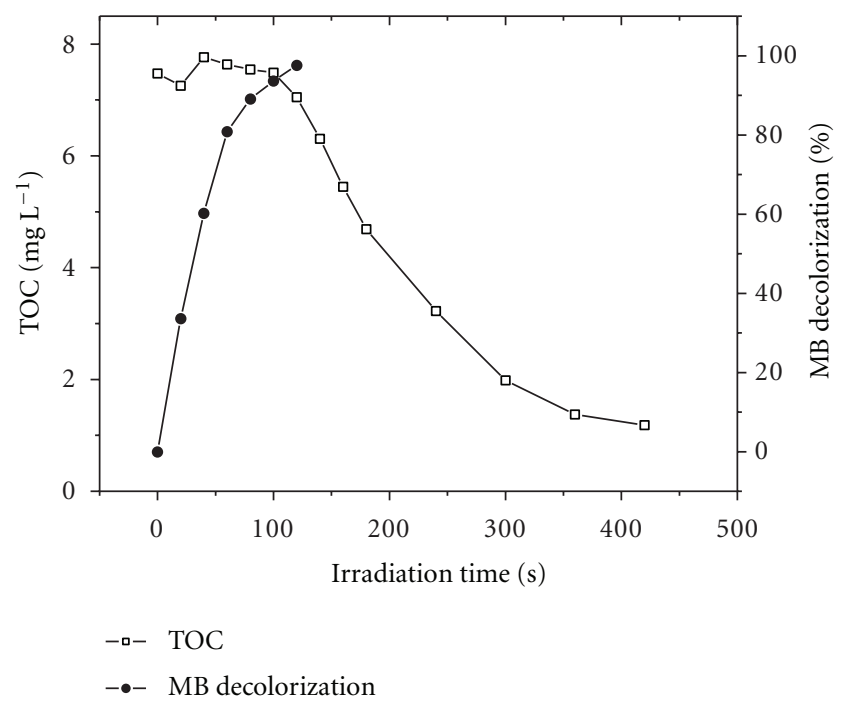

FIGURE 5: The TOC removal and decolorization efficiencies versus irradiation time. (Experimental conditions: photon flux $3.13 \times$ $10^{-6}$ einstein $\mathrm{cm}^{-2} \mathrm{~s}^{-1} ; \mathrm{TiO}_{2}, 0.01 \mathrm{~g} \mathrm{~L}^{-1}$; $\mathrm{MB}$ initial concentration $\left.20 \mathrm{mg} \mathrm{L}^{-1}\right)$.

infer that in HUP while MB molecules are being decomposed to lower-molecular-weight compounds, there are still enough electron-hole pairs and ${ }^{\circ} \mathrm{OH}$ radicals to mineralize the intermediates of $\mathrm{MB}$, which provides a higher efficiency in photocatalytic mineralization. In addition, the mineralization plateau observed (about $0.6 \mathrm{mg} \mathrm{L}^{-1}$ ) near $100 \mathrm{~s}$ was much lower than that in LUP (about $3 \mathrm{mg} \mathrm{L}^{-1}$ ), and the comparison of the two constant level of TOC values suggested that the stable products could be oxidized more easily in HUP than in LUP. It indicates that large numbers of electronhole pairs and $\cdot \mathrm{OH}$ radicals can also increase the rate of oxidation of stable products, dramatically enhancing the degree of mineralization in the photocatalytic reaction.

To further investigate the effect of the amount of excited electron-hole pairs on the photocatalytic mineralization procedure, we reduced excited electron-hole pairs by reducing the $\mathrm{TiO}_{2}$ concentration by two orders of magnitude to $0.01 \mathrm{~g} \mathrm{~L}^{-1}$ and maintaining the photon flux constant. The TOC removal and decolorization efficiencies with irradiation time are shown in Figure 5. During the decolorization time $(0-120 \mathrm{~s})$, there was only a small decrease of TOC. After the decolorization of the solution, TOC decreased sharply, reaching a terminal value of about TOC $1.2 \mathrm{mg} \mathrm{L}^{-1}$. Obviously, the mineralization procedure of this experiment is similar with LUP (Figure 4(b)). The two mineralization procedures have both been designed by two different methods of reducing excited electron-hole pairs. These results confirm the speculation, indicating that the amount of excited electron-hole pairs is truly the main reason for the different photocatalytic mineralization procedures.

\section{Conclusion}

The photocatalytic degradation of MB was investigated in HUP and LUP. Three criteria have been selected to compare both processes: (i) reaction rate and reaction time, (ii) the initial apparent photonic efficiency, and (iii) mineralization rate and mineralization degree. It was found that high UV photon flux is effective for accelerating the photocatalysis rate. Under optimal operational conditions, $99 \%$ decolorization of MB solution could be achieved within $30 \mathrm{~s}$ of UV irradiation time or more than $90 \%$ decolorization within $15 \mathrm{~s}$, and $95 \%$ removal of $9.75 \mathrm{mg} \mathrm{L}^{-1}$ TOC could be achieved within $120 \mathrm{~s}$. The analysis of initial apparent photonic efficiency shows the initial apparent photonic efficiency decreases with the increase of photon flux. Furthermore, we 
have established that a high density of electron-hole pairs is one of reasons that caused decline of initial apparent photonic efficiency at high photon flux photocatalytic reaction, and the reduction in the density of excited electronhole could actually improve the initial apparent photonic efficiency in high photon flux photocatalytic reaction. The obtained results in mineralization processes showed that high photon flux could dramatically improve the mineralization rate and enhance the degree of mineralization in the photocatalytic reaction, which is attributed to the large numbers of electron-hole pairs and ${ }^{\bullet} \mathrm{OH}$ radicals.

\section{References}

[1] C. A. Martínez-Huitle and E. Brillas, "Decontamination of wastewaters containing synthetic organic dyes by electrochemical methods: a general review," Applied Catalysis B, vol. 87, no. 3-4, pp. 105-145, 2009.

[2] Z. Wang, W. Ma, C. Chen, H. Ji, and J. Zhao, "Probing paramagnetic species in titania-based heterogeneous photocatalysis by electron spin resonance (ESR) spectroscopy-a mini review," Chemical Engineering Journal, vol. 170, no. 2-3, pp. 353-362, 2011.

[3] U. I. Gaya and A. H. Abdullah, "Heterogeneous photocatalytic degradation of organic contaminants over titanium dioxide: a review of fundamentals, progress and problems," Journal of Photochemistry and Photobiology C, vol. 9, no. 1, pp. 1-12, 2008.

[4] C. Quiñones, J. Ayala, and W. Vallejo, "Methylene blue photoelectrodegradation under UV irradiation on Au/Pd-modified $\mathrm{TiO}_{2}$ films," Applied Surface Science, vol. 257, no. 2, pp. 367$371,2010$.

[5] A. L. Linsebigler, G. Lu, and J. T. Yates, "Photocatalysis on $\mathrm{TiO}_{2}$ surfaces: principles, mechanisms, and selected results," Chemical Reviews, vol. 95, no. 3, pp. 735-758, 1995.

[6] S. M. Meunier, J. Gamage, Z. Duvnjak, and Z. Zhang, "Design and characterization of a novel rotating corrugated drum reactor for wastewater treatment," International Journal of Photoenergy, vol. 2010, Article ID 146743, 10 pages, 2010.

[7] L. Elsellami, F. Vocanson, F. Dappozze et al., "Kinetic of adsorption and of photocatalytic degradation of phenylalanine effect of $\mathrm{pH}$ and light intensity," Applied Catalysis A, vol. 380, no. 1-2, pp. 142-148, 2010.

[8] D. F. Ollis, E. Pelizzetti, and N. Serpone, "Photocatalyzed destruction of water contaminants," Environmental Science and Technology, vol. 25, no. 9, pp. 1522-1529, 1991.

[9] K. Okamoto, Y. Yamamoto, H. Tanaka, and A. Itaya, "Kinetics of heterogeneous photocatalytic decomposition of phenol over anatase $\mathrm{TiO}_{2}$ powder," Bulletin of the Chemical Society of Japan, vol. 58, no. 7, pp. 2023-2028, 1985.

[10] S. B. Kim and S. C. Hong, "Kinetic study for photocatalytic degradation of volatile organic compounds in air using thin film $\mathrm{TiO}_{2}$ photocatalyst," Applied Catalysis B, vol. 35 , no. 4, pp. 305-315, 2002.

[11] J. T. Carneiro, R. Berger, J. A. Moulijn, and G. Mul, "An internally illuminated monolith reactor: pros and cons relative to a slurry reactor," Catalysis Today, vol. 147, pp. S324-S329, 2009.

[12] S. Ahmed, M. G. Rasul, R. Brown, and M. A. Hashib, "Influence of parameters on the heterogeneous photocatalytic degradation of pesticides and phenolic contaminants in wastewater: a short review," Journal of Environmental Management, vol. 92, no. 3, pp. 311-330, 2011.
[13] C. G. Hatchard and C. A. Parker, "A new sensitive chemical actinometer II potassium ferrioxalate as a standard chemical actinometer," Proceedings of the Royal Society of London. Series A, vol. 235, no. 1203, pp. 518-536, 1956.

[14] I. K. Konstantinou and T. A. Albanis, " $\mathrm{TiO}_{2}$-assisted photocatalytic degradation of azo dyes in aqueous solution: kinetic and mechanistic investigations: a review," Applied Catalysis B, vol. 49, no. 1, pp. 1-14, 2004.

[15] A. Chatzitakis, C. Berberidou, I. Paspaltsis, G. Kyriakou, T. Sklaviadis, and I. Poulios, "Photocatalytic degradation and drug activity reduction of chloramphenicol," Water Research, vol. 42, no. 1-2, pp. 386-394, 2008.

[16] M. Muneer and D. Bahnemann, "Semiconductor-mediated photocatalyzed degradation of two selected pesticide derivatives, terbacil and 2,4,5-tribromoimidazole, in aqueous suspension," Applied Catalysis B, vol. 36, no. 2, pp. 95-111, 2002.

[17] L. Zhang, W. A. Anderson, and Z. Zhang, "Development and modeling of a rotating disc photocatalytic reactor for wastewater treatment," Chemical Engineering Journal, vol. 121, no. 2-3, pp. 125-134, 2006.

[18] O. K. Dalrymple, D. H. Yeh, and M. A. Trotz, "Removing pharmaceuticals and endocrine-disrupting compounds from wastewater by photocatalysis," Journal of Chemical Technology and Biotechnology, vol. 82, no. 2, pp. 121-134, 2007.

[19] E. E. Coyle and M. Oelgemöller, "Micro-photochemistry: photochemistry in microstructured reactors. The new photochemistry of the future?" Photochemical and Photobiological Sciences, vol. 7, no. 11, pp. 1313-1322, 2008.

[20] A. Houas, H. Lachheb, M. Ksibi, E. Elaloui, C. Guillard, and J. M. Herrmann, "Photocatalytic degradation pathway of methylene blue in water," Applied Catalysis B, vol. 31, no. 2, pp. 145-157, 2001. 


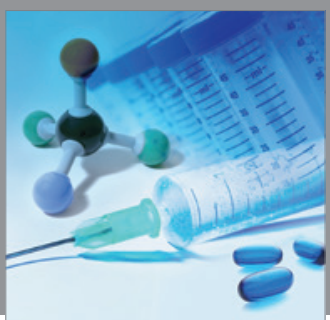

International Journal of

Medicinal Chemistry

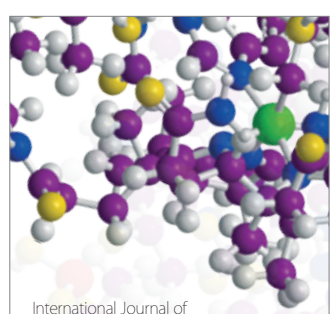

Carbohydrate Chemistry

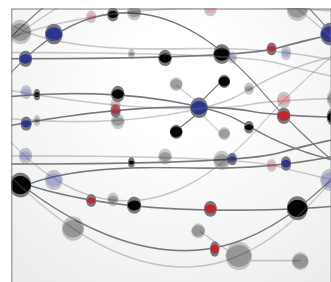

The Scientific World Journal
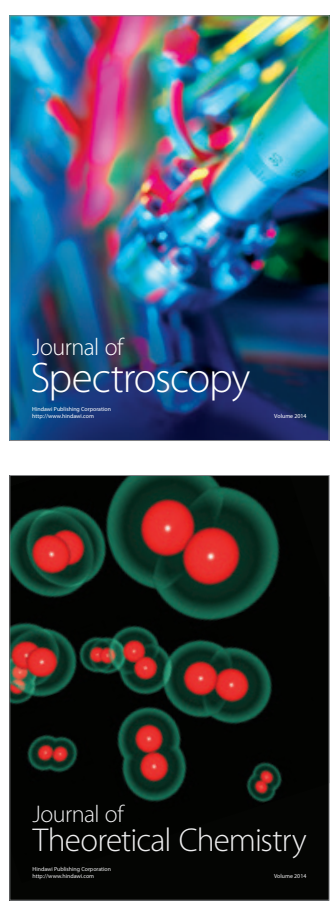
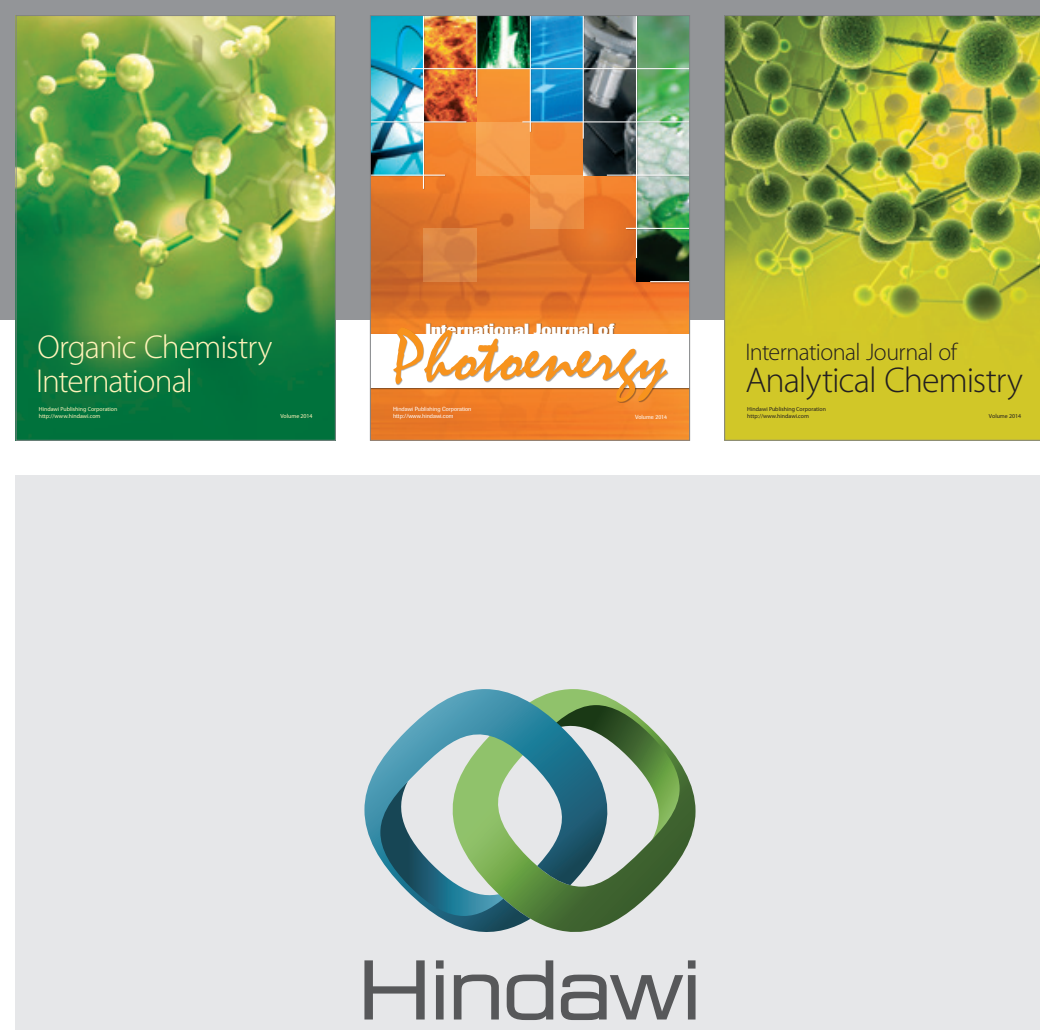

Submit your manuscripts at

http://www.hindawi.com
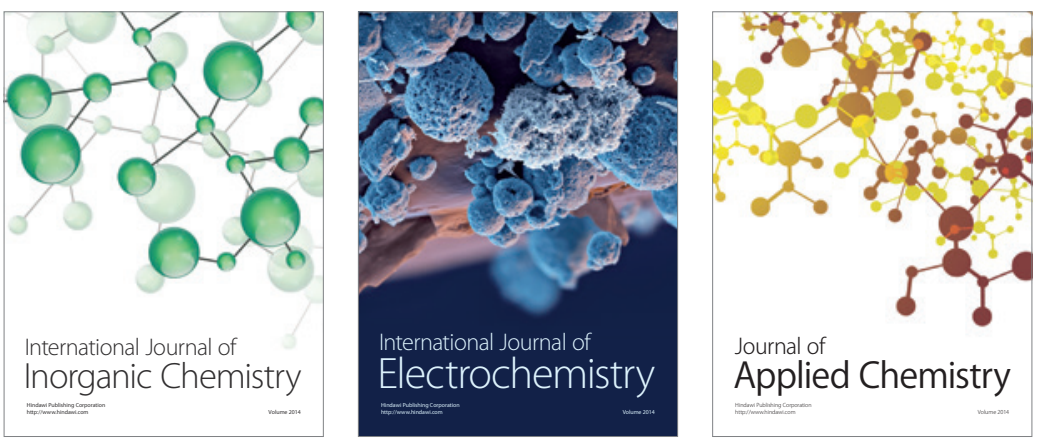

Journal of

Applied Chemistry
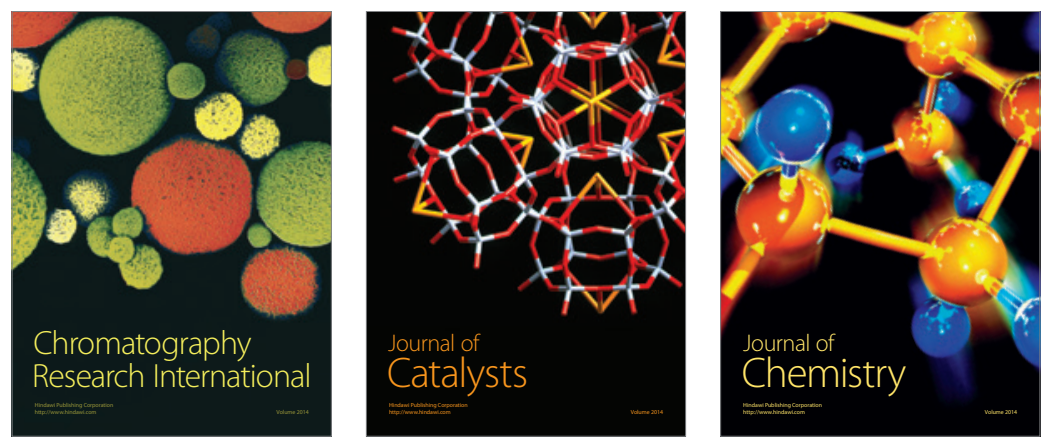
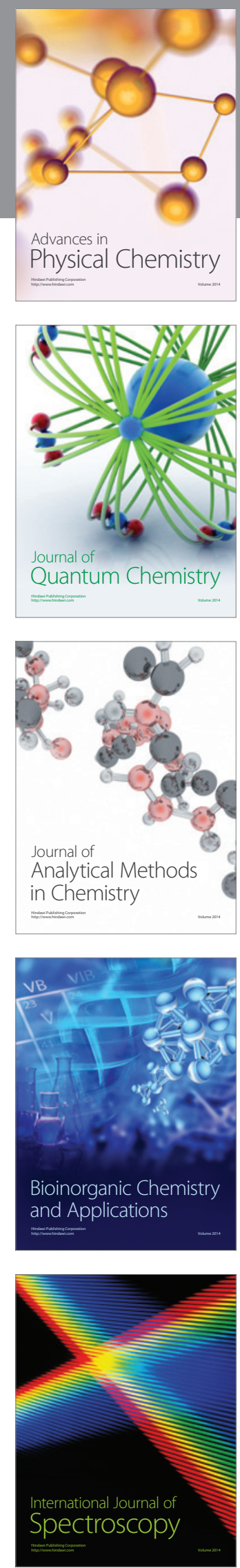